\title{
Foreword: Mediterranean diet and climatic change
}

\author{
Lluís Serra-Majem ${ }^{1,2, *}$, Anna Bach-Faig ${ }^{2}$, Gemma Miranda $^{2}$ and \\ Carmen Clapes-Badrinas ${ }^{2}$ \\ 'Department of Clinical Sciences, University of Las Palmas de Gran Canaria, Las Palmas de Gran Canaria, \\ Spain: ${ }^{2}$ Mediterranean Diet Foundation, C/Johann Sebastián Bach, 8 Entresol 2a, 08021 Barcelona, Spain
}

Submitted 13 May 2011: Accepted 12 August 2011

\begin{abstract}
Changes in diet, reducing animal products and increasing consumption of vegetables can not only benefit human health and the overall use of land, but can also play a decisive role in the politics of climate change mitigation. In this sense, the Mediterranean diet (MD) is presented as a sustainable cultural model, respectful of the environment, whose adherence in Mediterranean countries should contribute to mitigating climate change. The recognition of the MD as an Intangible Cultural Heritage of Humanity by UNESCO in 2010 obliges the Mediterranean Diet Foundation to continue waging this recovery process and to promote our ancient food traditions in a prism of sustainability and commitment to the environment.
\end{abstract}

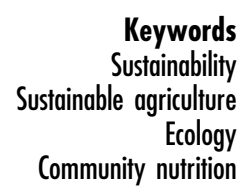

In this special issue on collecting the major papers regarding the VIII International Congress of the Mediterranean Diet, organised in Barcelona in 2010, special emphasis is placed on issues concerning the sustainability of food and how the production and transportation of food contributes to enhancing the consequences of climate change.

Climate change is a reality that is already on the political agenda of international organisations and governments. In general, politicians often focus on the energy sector to mitigate this change, whereas agriculture and livestock receive little attention. However, they represent approximately $20 \%$ of greenhouse gas emissions and $80 \%$ of the land surface used by humans ${ }^{(1)}$.

From a nutritional standpoint, we know that there is a need to moderate the consumption of red meat for strictly health reasons ${ }^{(2)}$. In addition, we know that there are climatic reasons supporting this recommendation. Reducing meat consumption by $50 \%$, for example, would have important implications in: (i) decreasing land devoted to pastures and crops, with the consequent generation of carbon from vegetation; (ii) reducing deforestation intended to obtain crops such as soyabeans and other vegetables for animal feed; and (iii) reducing methane and nitrogen dioxide emissions substantially $(9-10 \%)^{(3,4)}$.

The changes in diet can therefore not only produce benefits in human health and the overall use of land, but can also play a decisive role in the policies to mitigate climate change ${ }^{(4)}$.

In an interesting prediction model, Stehfest et $a l^{(4)}$, using four variants of food types (low total meat, low beef and ruminant, low in animal products, healthy or rich in vegetables), analyse the impact between the years 2000 and 2050 of these dietary patterns on some climate change indicators such as livestock production, land use and methane and nitrous oxide emission. The authors conclude on the need to promote some dietary changes within the policies of mitigating climate change. CarlssonKanyana and Gonzalez ${ }^{(5)}$ have analysed the greenhouse gas emissions (mainly carbon dioxide and methane) resulting from the production of various food items, also taking into account the environmental costs of transport distance from the place of production to the point of consumption.

The Mediterranean diet (MD) understood not only as a set of food items but also as a culture on ways of producing and elaborating food is an example of sustainability $^{(6)}$. There are examples on how the abandonment of traditional farming practices, livestock and fisheries affects the very sustainability of the MD and its survival. Hence, the importance of it being included on UNESCO's Intangible Cultural Heritage of Humanity list $^{(7)}$. Its cultural aspects need to be preserved to ensure its own sustainability as well as the cultivation and harvesting methods ${ }^{(8)}$, and hence the landscapes.

In the first paper in the special issue ${ }^{(9)}$, an expert committee from the Mediterranean Diet Foundation (MDF) in collaboration with other institutions presents the new graphic representation of the MD pyramid, conceived as a simplified main frame to be adapted to the different contexts of the Mediterranean region. Its semiquantitative representation incorporates relative proportions and frequency of the MD pattern food groups, as well as the concepts of seasonality and local products, physical activity, socialisation and so on. Since the recognition of the MD as an Intangible Cultural Heritage of Humanity by UNESCO in 2010 and for its contribution 
to health and general well-being, we hope to contribute to much better adherence and to its preservation with this new graphic representation.

In a second paper, Burlingame and Dernini ${ }^{(10)}$ emphasise that the acknowledgement of the MD as a sustainable diet needs the development of new crosscutting intersectorial case studies to demonstrate further the synergies among nutrition, biodiversity and sustainability expressed by the MD for the benefit of present and future generations. Berry et $a l^{(11)}$ describe in their paper how the biblical traditional diet, including the seven species (whole grains, fish, wine, pomegranates, figs, walnuts and extra virgin olive oil) and additional Mediterranean fruits, has great health advantages, especially for CVD. In addition to the diet, lifestyle adaptation that involves increasing physical activity and organised meals, together with healthy food choices, is consistent with the traditional MD. Casas-Agustench et $a l^{(12)}$ explain that, like other foods, nuts have a wide variety of cultural connections to the areas where they grow and to the people who live there or eat them. History, symbolism and legends reveal the ancient tradition of nuts and how they are related to the lives of our ancestors.

In an interesting paper by Defoort et al. ${ }^{(13)}$, MD appears efficient in improving postprandial lipemia (TAG and ApoB48, a marker of intestinally derived chylomicrons), a recently acknowledged CVD risk, in men and women with moderate cardiovascular risk. In addition, Martinez-Gonzalez et al. ${ }^{(14)}$ review the evidence on the association between fruit and vegetable (F\&V) consumption and risk of major chronic disease and assess trends in the prevalence of low F\&V consumption in a cohort of university graduates. Gil et al. empathise the benefits of wholegrain cereals and bread for many noncommunicable diseases ${ }^{(15)}$. In addition, Escrich et al. $^{(16)}$ pooling data from sixteen animal experimental series analysing the effects of dietary lipids on mammary carcinogenesis concluded that consumption of extra virgin olive oil in moderate quantities and throughout the lifetime appears to be a healthy choice and may favourably influence a reduction of breast cancer risk. De Lorgeril and Salen ${ }^{(17)}$ recognise that there is now a consensus about recommending the MD pattern for secondary prevention of CHD because no other dietary pattern has been successfully tested so far in these patients. The most important aspect, in contrast with the pharmacological prevention of CHD (including lowering of cholesterol), is that the MD results in a striking effect on survival. They also conclude that the traditional MD is effective in reducing both coronary atherosclerosis/thrombosis and the risk of fatal complications such as sudden cardiac death and chronic heart failure. Both De Lorgeril and Renaud $^{(18)}$ were the scientists responsible for the Lyon Heart Study and for the important experiment that represents a key landmark for the recognition of the MD, and for their outstanding careers, they were recognised

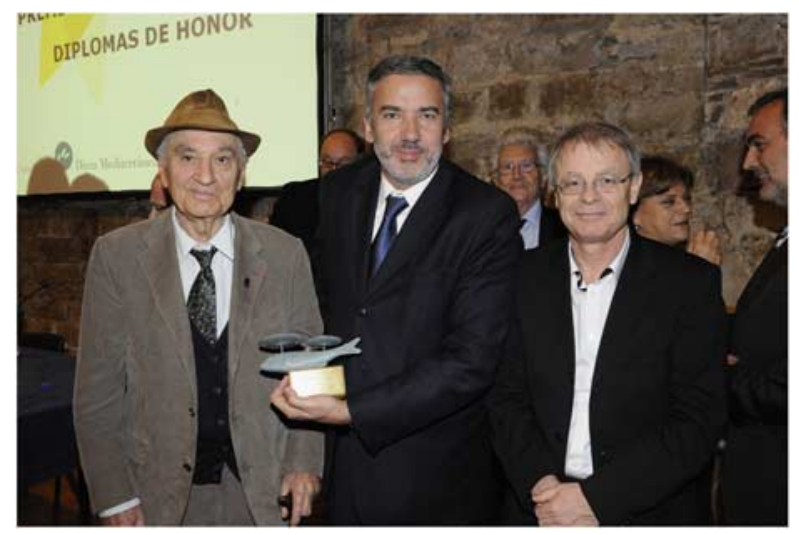

Fig. 1 (colour online) Professors Serge Renaud, Lluis SerraMajem and Michel de Lorgeril after the VIII Grande Covian Award Ceremony held in Barcelona on 25 March 2010

with the MDF's VIII Grande Covian Award (Jury: Antonia Trichopoulou, Denis Lairon, Leda Chatzi, Jordi SalasSalvadó, Carlo La Vecchia, Silvia Franceschi, Walter C Willet, Miguel Angel Martínez and Lluís Serra-Majem (Chairman)). Figure 1 illustrates the historical moment when these researchers shared the common prestigious recognition in Barcelona, 25 March 2010.

Milà-Villarroel et $a l^{(19)}$ in their paper comparing and evaluating the reliability of different indexes of adherence to the MD conclude that indexes perform quite well in measuring the adherence to MD. However, the lack of high correlation among some of them indicates the need for better agreement on the components involved in the MD pattern.

Finally, Medina(20) ends the special issue with a paper that dissects Mediterranean food and diet as a proximity model of consumption that can be, from a local Mediterranean point of view, a sustainable resource for the Mediterranean area.

This collection of selected papers updates once again the trends and developments around the MD, and with that, the MDF aims to contribute to improving its outreach, increasing awareness among health and nutrition professionals and ultimately improving compliance and projection at the population level in a coherent and sustainable way.

\section{References}

1. Serra-Majem L (2010) Nutricion comunitaria y sostenibilidad: concepto y evidencias. Rev Esp Nutr Comunitaria 16, 35-40.

2. Willett WC (2001) Eat, Drink, and be Healthy: The Harvard Medical School Guide to Healthy Eating. New York: Simon $\&$ Schuster.

3. Smil V (2002) Eating meat: evolution, patterns, and consequences. Popul Dev Rev 28, 599-639.

4. Stehfest E, Bouwman L, van Vuuren DP et al. (2009) Climate benefits of changing diet. Climatic Change 95, 83-102.

5. Carlsson-Kanyama A \& González AD (2009) Potential contributions of food consumption patterns to climate change. Am J Clin Nutr 89, 1704S-1709S. 
6. Gussow JD (1995) Mediterranean diets: are they environmentally responsible? Am J Clin Nutr 61, Suppl. 6, 1383S-1389S.

7. Fundación Dieta Mediterránea (2010) Dieta Mediterránea Candidatura a Patrimonio Inmaterial de la Humanidad. http://candidaturadietamediterranea.org (accessed February 2010).

8. Duarte F, Jones N \& Fleskens L (2008) Traditional olive orchards on sloping land: sustainability or abandonment? J Environ Manage 89, 86-98.

9. Bach-Faig A, Berry EM, Lairon D et al. (2011) Mediterranean diet pyramid today. Science and cultural updates. Public Health Nutr 14, Suppl. 1, 2274-2284.

10. Burlingame B \& Dernini S (2011) Sustainable diets: the Mediterranean diet as an example. Public Health Nutr 14, Suppl. 1, 2285-2287.

11. Berry EM, Arnoni Y \& Aviram M (2011) The middle eastern and biblical origins of the Mediterranean diet. Public Health Nutr 14, Suppl. 1, 2288-2295.

12. Casas-Agustench P, Salas-Huetos A \& Salas-Salvadó J (2011) Mediterranean nuts: origins, ancient medicinal benefits and symbolism. Public Health Nutr 14, Suppl. 1, 2296-2301.

13. Defoort C, Vincent-Baudry S \& Lairon D (2011) Effects of 3-month Mediterranean-type diet on postprandial TAG and apolipoprotein B48 in the Medi-RIVAGE cohort. Public Health Nutr 14, Suppl. 1, 2302-2308.
14. Martinez-Gonzalez MA, de la Fuente-Arrillaga C, Lopez-del Burgo C et al. (2011) Low consumption of fruit and vegetables and risk of chronic disease: a review of the epidemiological evidence and temporal trends among Spanish graduates. Public Health Nutr 14, Suppl. 1, 2309-2315.

15. Gil A, Ortega RM \& Maldonado J (2011) Wholegrain cereals and bread: a duet of the Mediterranean diet for the prevention of chronic diseases. Public Health Nutr 14, Suppl. 1, 2316-2322.

16. Escrich E, Moral R \& Solanas M (2011) Olive oil, an essential component of the Mediterranean diet, and breast cancer. Public Health Nutr 14, Suppl. 1, 2323-2332.

17. De Lorgeril M \& Salen P (2011) Medioterranean diet in secondary prevention of CHD. Public Health Nutr 14, Suppl. 1, 2333-2337.

18. De Lorgeril M, Renaud S, Mamelle M et al. (1994) Mediterranean alpha-linolenic acid-rich diet in secondary prevention of coronary heart disease. Lancet 343, 1454-1459.

19. Milà-Villarroel R, Bach-Faig A, Puig J et al. (2011) Comparison and evaluation of reliability of different indexes of adherence to the Mediterranean diet. Public Health Nutr 14, Suppl. 1, 2338-2345.

20. Medina FX (2011) Food consumption and civil society: Mediterranean diet as a sustainable resource for the Mediterranean area. Public Health Nutr 14, Suppl. 1, 2346-2349. 